\title{
Cordycepin increases sensitivity of Hep3B human hepatocellular carcinoma cells to TRAIL-mediated apoptosis by inactivating the JNK signaling pathway
}

\author{
HYE HYEON LEE ${ }^{1}$, JIN-WOO JEONG ${ }^{2}$, JUN HYUK LEE ${ }^{3}$, GI-YOUNG KIM ${ }^{4}$, JAEHUN CHEONG ${ }^{5}$, \\ YONG KEE JEONG ${ }^{1}$, YOUNG HYUN YOO $^{6}$ and YUNG HYUN CHOI ${ }^{7,8}$
}

\footnotetext{
${ }^{1}$ Department of Biotechnology and Medi-Farm Industrialization Research Center, Dong-A University, Busan 604-714;

${ }^{2}$ Center for Core Research Facilities, Daegu Gyeongbuk Institute of Science and Technology, Daegu 711-873;

${ }^{3}$ Biotechnology Examination Division, Chemistry and Biotechnology Examination Bureau, Korean Intellectual Property Office, Daejeon 302-701; ${ }^{4}$ Laboratory of Immunobiology, Department of Marine Life Sciences, Jeju National University, Jeju 690-756; ${ }^{5}$ Department of Molecular Biology, College of Natural Sciences, Pusan National University, Busan 609-735; ${ }^{6}$ Department of Anatomy and Cell Biology and Mitochondria Hub Regulation Center, College of Medicine, Dong-A University, Busan 602-714; ${ }^{7}$ Department of Biochemistry, Dongeui University College of Oriental Medicine, Busan 614-052; ${ }^{8}$ Anti-Aging Research Center and Blue-Bio Industry RIC, Dongeui University, Busan 614-714, Republic of Korea
}

Received March 26, 2013; Accepted June 5, 2013

DOI: 10.3892/or.2013.2589

\begin{abstract}
Resistance to tumor necrosis factor-related apoptosis-inducing ligand (TRAIL)-induced apoptosis has been reported in various cancer cells. Cordycepin, a specific polyadenylation inhibitor, is the main functional component in Cordyceps militaris, which possesses many pharmacological activities including antitumor and anti-inflammation. In the present study, we demonstrated that treatment of cordycepin sensitized TRAIL-resistant Hep3B human hepatocellular carcinoma cells to TRAIL-mediated apoptosis as evidenced by formation of apoptotic bodies, chromatin condensation and accumulation of cells in the sub-G1 phase. The induction of apoptosis following co-treatment with cordycepin and TRAIL in Hep3B cells appeared to be correlated with modulation of Bcl-2 family protein expression and activation of the caspase cascade, which resulted in the cleavage of poly(ADP-ribose) polymerase and $\beta$-catenin. In addition, cordycepin treatment also inhibited activation of c-Jun N-terminal kinase (JNK).
\end{abstract}

Correspondence to: Dr Young Hyun Yoo, Department of Anatomy and Cell Biology and Mitochondria Hub Regulation Center, College of Medicine, Dong-A University, Busan 602-714, Republic of Korea E-mail: yhyoo@dau.ac.kr

Dr Yung Hyun Choi, Department of Biochemistry, Dongeui University College of Oriental Medicine, San 45, Yangjung-dong Busanjin-gu, Busan 614-052, Republic of Korea

E-mail: choiyh@deu.ac.kr

Key words: cordycepin, TRAIL, Hep3B cells, apoptosis, c-Jun $\mathrm{N}$-terminal kinase
Pretreatment with SP600125, a JNK inhibitor, resulted in a significantly increased sub-G1 population and caspase activity in cordycepin plus TRAIL-mediated apoptosis. Taken together, these results indicate that JNK acts as a key regulator of apoptosis in response to combined treatment with cordycepin and TRAIL in human hepatocellular carcinoma Hep3B cells.

\section{Introduction}

Selective and specific induction of apoptotic cell death in cancer cells has been increasingly recognized as a promising therapeutic approach for the treatment of many types of cancers. The tumor necrosis factor (TNF)-related apoptosisinducing ligand (TRAIL), a member of the TNF ligand superfamily, is considered as a promising anticancer agent in cancer therapy due to its ability to induce apoptosis in a variety of tumor cell types while having no significant sideeffects on normal cells $(1,2)$. Therefore, the discovery of agents that induce TRAIL and promote TRAIL-mediated apoptotic cell death has received considerable attention. TRAIL induces apoptosis in cancer cells via the death receptor pathway using a mechanism similar to that of TNF (2-4). Although many cancer cells express functional TRAIL receptors, such as death receptor 4 (DR4) and DR5, resistance to TRAIL is common due to a decreased level or mutation in DR4 and DR5 or the loss of distal signaling cascades (4-6). For these reasons, TRAIL is not recommended for use as a single agent; therefore, chemotherapeutic agents that can sensitize cells to TRAIL-mediated apoptosis are urgently needed.

The polyadenylation inhibitor cordycepin (3'-deoxyadenosine) is an active component of the caterpillar fungus Cordyceps militaris. Due to the absence of oxygen in the $3^{\prime}$ position of its ribose moiety, incorporation of cordycepin 
during RNA synthesis results in termination of chain elongation $(7,8)$. This activity has been well described in vitro with purified RNA polymerases and poly(A) polymerases from a number of organisms, including yeasts and mammals $(9,10)$. Cordycepin has anticancer activities including induction of apoptosis, DNA double-strand break activity, and cell cycle arrest in cancer cells (11-15). This compound also inhibits metastasis and angiogenesis (16-19). Despite these observations, the molecular mechanisms underlying the anticancer effects of cordycepin on TRAIL-mediated apoptosis have not been fully elucidated.

In the present study, we investigated the mechanisms involved in cordycepin-induced apoptosis in TRAIL-resistant Hep3B human hepatocellular carcinoma cells. Our results indicate that a combined treatment with subtoxic concentrations of cordycepin and TRAIL dramatically induced Hep3B cell death through activation of caspase and loss of mitochondrial membrane potential (MMP) via inhibition of c-Jun N-terminal kinase (JNK) signaling. Therefore, a combined treatment with cordycepin and TRAIL may synergistically stimulate and accelerate the JNK-mediated apoptotic signaling pathway.

\section{Materials and methods}

Regents and antibodies. Cordycepin (MW, 251.2; product no. C3394) from $C$. militaris, 4',6-diamidino-2-phenylindole (DAPI), N-acetyl-L-cysteine, 3-(4,5-dimethylthiazol-2-yl)2,5-diphenyltetrazolium bromide (MTT), 5,5',6,6'-tetrachloro-1,1',3,3' tetraethylbenzimidazolylcarbocyanine iodide (JC-1) and propidium iodide (PI) were obtained from Sigma-Aldrich Chemical Co. (St. Louis, MO, USA). Caspase activity assay kits were obtained from R\&D Systems (Minneapolis, MN, USA). An enhanced chemiluminescence (ECL) kit and RNeasy kit were purchased from Amersham Corp. (Arlington Heights, IL, USA) and Qiagen (La Jolla, CA, USA), respectively. RPMI-1640 medium and fetal bovine serum (FBS) were purchased from Invitrogen Life Technologies (Carlsbad, CA, USA) and Gibco-BRL (Gaithersburg, MD, USA), respectively. All other chemicals were purchased from Sigma-Aldrich. Antibodies against cIAP-1, cIAP-2, XIAP, Bcl-2, Bcl-xL, Bax, Bid, poly(ADP-ribose) polymerase (PARP), $\beta$-catenin, capase-3, -8 and -9 were purchased form Santa Cruz Biotechnology Inc. (Santa Cruz, CA, USA). Antibodies against extracellular signal-regulated kinase (ERK), phospho (p)-ERK, p38 mitogen-activated protein kinase (MAPK), p-p38 MAPK, JNK, p-JNK, Akt and p-Akt were purchased from BD Biosciences (San Jose, CA, USA). Antibody against actin was from Sigma-Aldrich. Peroxidase-labeled donkey anti-rabbit and sheep anti-mouse immunoglobulin were purchased from Amersham Corp.

Cell culture and MTT assay. Hep3B human hepatocellular carcinoma cells were obtained from the American Type Culture Collection (Manassas, VA, USA). Cells were cultured at $37^{\circ} \mathrm{C}$ in a $5 \% \mathrm{CO}_{2}$ humidified incubator, and maintained in RPMI-1640 culture medium containing 10\% heat-inactivated FBS. For the cell viability assay, cells were grown to $70 \%$ confluence and treated with the indicated concentrations of cordycepin, TRAIL, or a combined treatment (cordycepin plus TRAIL). After treatment, MTT working solution was added to 6-well culture plates and incubated continuously at $37^{\circ} \mathrm{C}$ for $2 \mathrm{~h}$. The culture supernatant was removed from the wells, and DMSO was added to dissolve the formazan crystals. The absorbance of each well was measured at $540 \mathrm{~nm}$ with an enzyme-linked immunosorbent assay (ELISA) reader (Molecular Devices, Sunnyvale, CA, USA).

Nuclear staining. After treatment with cordycepin and TRAIL alone or together for the indicated times, the cells were harvested, washed with phosphate-buffered saline (PBS) and fixed with $3.7 \%$ paraformaldehyde in PBS for $10 \mathrm{~min}$ at room temperature. Fixed cells were washed with PBS, and stained with $2.5 \mu \mathrm{g} / \mathrm{ml}$ DAPI solution for $10 \mathrm{~min}$ at room temperature. The cells were washed 2 more times with PBS and analyzed via a fluorescence microscope (Carl Zeiss, Oberkochen, Germany).

Flow cytometric analysis for assessment of the sub-G1 phase population. The cells were washed twice with cold PBS and then centrifuged. The resulting pellet was fixed in $75 \%(\mathrm{v} / \mathrm{v})$ ethanol for $1 \mathrm{~h}$ at $4^{\circ} \mathrm{C}$. The cells were washed once with PBS and resuspended in cold PI solution $(50 \mu \mathrm{g} / \mathrm{ml})$ containing RNase A $(0.1 \mathrm{mg} / \mathrm{ml})$ in PBS for $30 \mathrm{~min}$ in the dark. Flow cytometric analyses were performed using FACSCalibur (Becton-Dickinson, San Jose, CA, USA). Forward light scatter characteristics were used to exclude cell debris from the analysis. The sub-G1 population was calculated to estimate the apoptotic cell population.

Determination of caspase activity. Caspase activities were determined by colorimetric assays using caspase-3, -8 and -9 activation kits according to the manufacturer's protocol. The kits utilize synthetic tetrapeptides labeled with p-nitroaniline. Briefly, the cells were lysed in the supplied lysis buffer. The supernatants were collected and incubated with the supplied reaction buffer containing dithiothreitol (DTT) and substrates at $37^{\circ} \mathrm{C}$. Caspase activity was determined by measuring changes in absorbance at $405 \mathrm{~nm}$ using an ELISA reader.

RNA extraction and reverse transcription-polymerase chain reaction $(R T-P C R)$. Total RNA was prepared using an RNeasy kit and primed with random hexamers to synthesize complementary DNA using AMV reverse transcriptase (Amersham Corp.) according to the manufacturer's instructions. PCR was carried out in a Mastercycler (Eppendorf, Hamburg, Germany) with the indicated primers. Conditions for the PCR reactions were, $1 \mathrm{x}\left(94^{\circ} \mathrm{C}\right.$ for $\left.3 \mathrm{~min}\right) ; 35 \mathrm{x}\left(94^{\circ} \mathrm{C}\right.$ for $45 \mathrm{sec}, 58^{\circ} \mathrm{C}$ for $45 \mathrm{sec}$ and $72^{\circ} \mathrm{C}$ for $\left.1 \mathrm{~min}\right)$; and $1 \mathrm{x}\left(72^{\circ} \mathrm{C}\right.$ for $\left.10 \mathrm{~min}\right)$. Amplification products obtained by PCR were electrophoretically separated on $1 \%$ agarose gels and visualized by ethidium bromide staining.

Protein extraction and western blotting. The cells were harvested and lysed with lysis buffer (20 mM sucrose, $1 \mathrm{mM}$ EDTA, $20 \mu \mathrm{M}$ Tris-Cl, pH 7.2, 1 mM DTT, $10 \mathrm{mM} \mathrm{KCl,}$ $1.5 \mathrm{mM} \mathrm{MgCl}{ }_{2}$, and $5 \mu \mathrm{g} / \mathrm{ml}$ aprotinin) for $30 \mathrm{~min}$. Protein concentration was measured using a Bio-Rad protein assay (Bio-Rad Laboratories, Hercules, CA, USA) according to the manufacturer's instructions. For western blot analysis, an 


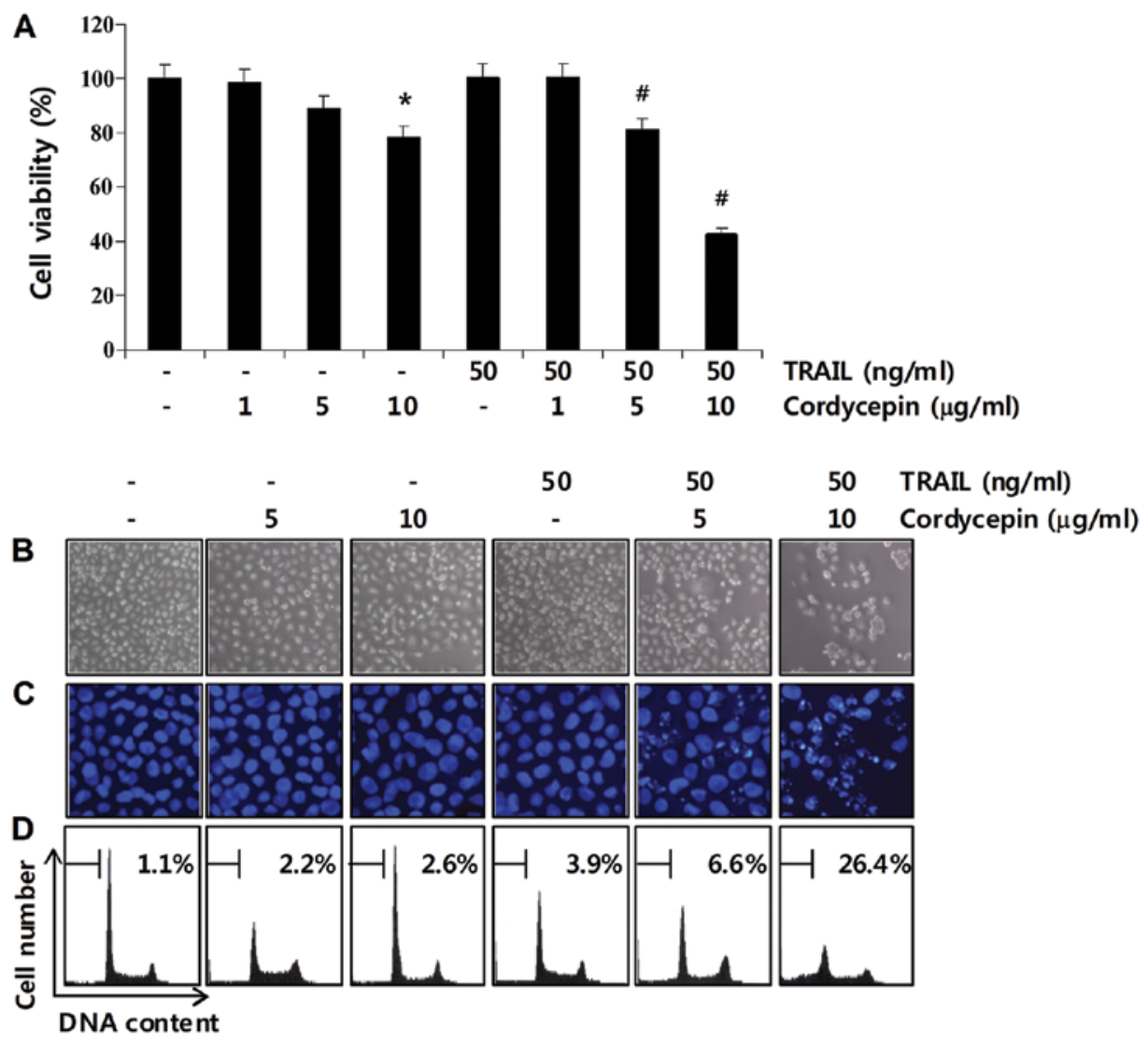

Figure 1. Effects of cordycepin and TRAIL on cell proliferation in Hep3B cells. Hep3B cells were seeded at $1 \times 10^{5}$ cells/ml. On the second day, the cells were treated with the indicated concentrations of cordycepin for $30 \mathrm{~min}$ and further treated with or without $50 \mathrm{ng} / \mathrm{ml} \mathrm{TRAIL}$ for $24 \mathrm{~h}$. (A) Cell viability was assessed by the metabolic dye-based MTT assay. Statistical significance was obtained from 3 independent experiments using the Student's t-test ("p $<0.05$ vs. untreated control; $" \mathrm{p}<0.05$ vs. TRAIL-treated cells). (B) Cell morphology was visualized with an inverted microscope. (C) After fixation, cells were stained with DAPI solution. Stained nuclei were then observed under a fluorescence microscope using a blue filter (magnification, x400). (D) Cells were evaluated for sub-G1 DNA content to quantify the degree of apoptosis, which represents the fractions undergoing apoptotic DNA degradation, using a flow cytometer. Results are expressed as the means \pm standard deviation of 2 separate experiments.

equal amount of protein was subjected to electrophoresis on SDS-polyacrylamide gels and was transferred by electroblotting to a nitrocellulose membrane (Schleicher \& Schuell, Keene, NH, USA). The blots were probed with the desired antibodies for $1 \mathrm{~h}$, incubated with the diluted enzyme-linked secondary antibody, and visualized with an ECL solution according to the recommended procedure.

Measurement of MMP $\left(\Delta \Psi_{m}\right)$. The MMP of intact cells was measured by DNA flow cytometry with the lipophilic cation JC-1. JC-1 is a rationmetric, dual-emission fluorescent dye that is internalized and concentrated by respiring mitochondria and reflects changes in MMP in living cells. There are two excitation wavelengths. At low values of MMP, JC-1 remains a monomer (FL-1, green fluorescence; $527 \mathrm{~nm}$ ) whereas it forms aggregates at high MMP (FL-2, red fluorescence; $590 \mathrm{~nm}$ ) according to the recommended procedure (20). Cells were trypsinized, the cell pellets were resuspended in PBS, and incubated with $10 \mu \mathrm{M} \mathrm{JC}-1$ for $30 \mathrm{~min}$ at $37^{\circ} \mathrm{C}$. The cells were subsequently washed once with cold PBS, suspended and analyzed by flow cytometry.

Statistical analysis. All data are presented as means \pm standard deviation. Significant differences among the groups were determined using the unpaired Student's t-test. A p-value $<0.05$ was considered to indicate a statistically significant result. All values were obtained from at least 2 or 3 independent experiments.

\section{Results}

Induction of apoptosis by co-treatment with cordycepin and TRAIL in Hep3B cells. We first assessed whether cordycepin sensitizes Hep3B cells to TRAIL-mediated apoptosis. Treatment with $50 \mathrm{ng} / \mathrm{ml}$ TRAIL resulted in negligible growth inhibition of Hep3B cells at $24 \mathrm{~h}$ (Fig. 1A), suggesting that this cell type is resistant to TRAIL-induced apoptosis. We next examined the cytotoxic effects of cordycepin alone or in combination with TRAIL in Hep3B cells. The concentrations $(1-10 \mu \mathrm{g} / \mathrm{ml})$ of cordycepin alone used in this study did not significantly induce morphological changes or inhibit growth. However, cell viability was significantly inhibited by the co-treatment with cordycepin and TRAIL (Fig. 1A) indicating that the combination of cordycepin and TRAIL substantially induces cell death. To investigate whether decreased cell viability by the combined treatment was due to apoptotic signaling, morphological changes and sub-G1 phase populations of Hep3B cells were determined using DAPI staining and flow 


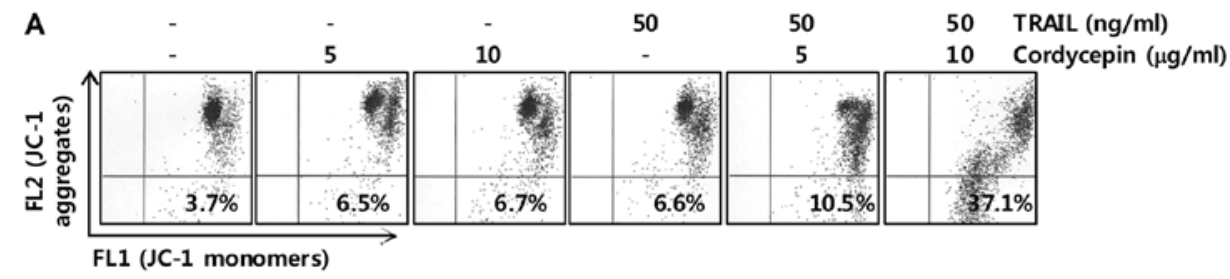

C

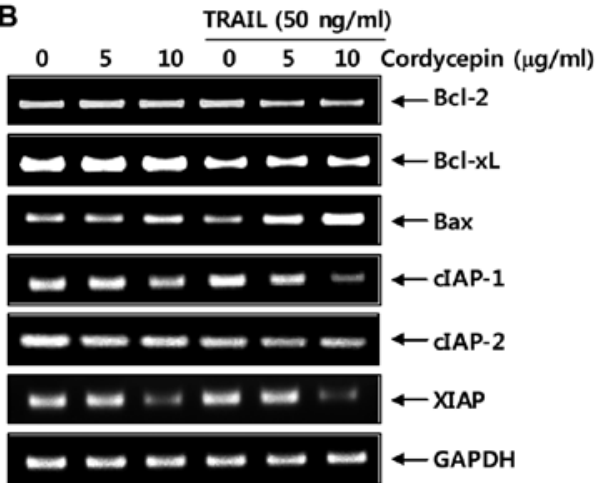

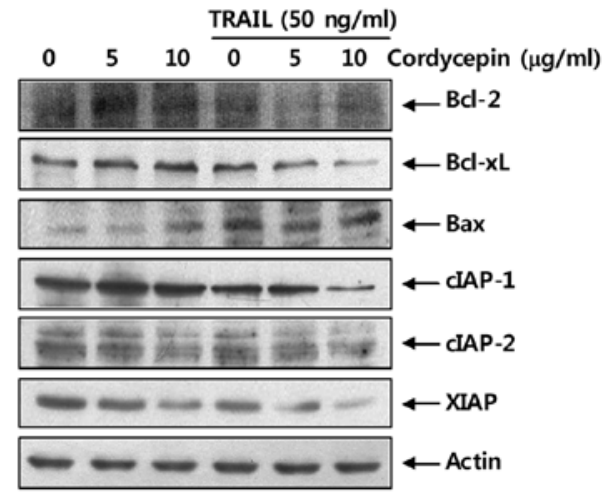

Figure 2. Effects of cordycepin and TRAIL on the levels of apoptosis-related factors and mitochondrial membrane potential (MMP) values in Hep3B cells. Cells were pretreated with the indicated concentrations of cordycepin for $30 \mathrm{~min}$, and subsequently incubated with TRAIL (50 ng/ml) for $24 \mathrm{~h}$. (A) The cells were stained with JC-1 and then incubated at $37^{\circ} \mathrm{C}$ for $20 \mathrm{~min}$, after which mean JC-1 fluorescence intensity was detected using a flow cytometer. Data are expressed as the means \pm standard deviation of 2 independent experiments. (B) Total RNA was isolated using an RNeasy kit, and RT-PCR was performed using the indicated primers. The amplified PCR products were run on $1 \%$ agarose gels and visualized with EtBr staining. GAPDH was used as the housekeeping control gene. (C) The cells were lysed and equal amounts of cell lysates were separated by SDS-polyacrylamide gel electrophoresis and transferred to nitrocellulose membranes. The membranes were probed with the indicated antibodies. An ECL detection system was used to visualize the proteins. Actin was used as the internal control.

cytometric analysis, respectively. As shown in Fig. 1B and C, a significant number of cells co-treated with cordycepin and TRAIL were observed with apoptotic shrinkage, chromatin condensation, loss of nuclear construction and formation of apoptotic bodies, whereas these features were not observed in control cells or cells treated with cordycepin or TRAIL alone. Additionally, treatment of Hep3B cells with a combination of cordycepin and TRAIL significantly increased the accumulation of sub-G1 phase cells, whereas treatment with cordycepin or TRAIL alone did not (Fig. 1D). These results showed that the combined treatment of cordycepin and TRAIL sensitized TRAIL-resistant Hep3B cells to apoptosis.

Effects of cordycepin and TRAIL co-treatment on the expression of Bcl-2 and IAP family members and MMP values. Mitochondria appear to play a central role in apoptosis. Thus, they have been a major focus of recent studies. The early events that occur during apoptotic cell death are mitochondrial depolarization and loss of pro-apoptotic factors from the mitochondrial inter-membrane space $(21,22)$. As shown in Fig. 2A, treatment of cells with cordycepin or TRAIL alone induced a slight loss of MMP in Hep3B cells; however, combined treatment with cordycepin and TRAIL caused a significant concentration-dependent induction of MMP loss. In particular, the anti-apoptotic Bcl-2 family molecules such as Bcl-2 and $\mathrm{Bcl}-\mathrm{xL}$, and IAP family members protect some tumor cell lines from TRAIL-induced apoptosis (22-24); therefore, we investigated the expression levels of members belonging to the Bcl-2 and IAP family. As shown in Fig. 2B and C, the mRNA and protein levels of anti-apoptotic $\mathrm{Bcl}-2$, Bcl-xL, cIAP-1, cIAP-2 and XIAP were reduced in response to treatment with cordycepin plus TRAIL, whereas the levels of pro-apoptotic Bax increased markedly. Collectively, these results indicate that downregulation of $\mathrm{Bcl}-2$ and $\mathrm{Bcl}-\mathrm{xL}$, and IAP family member expression and increased loss of MMP are associated with cordycepin-mediated sensitization of Hep3B cells to TRAIL-mediated apoptosis.

Effects of co-treatment with cordycepin and TRAIL on caspase activation. Caspases act as important mediators of apoptosis and contribute to the overall apoptotic morphology by cleaving various cellular substrates $(24,25)$. Therefore, we next examined whether caspases were actually activated during cordycepin plus TRAIL-induced cell death in Hep3B cells. As shown in Fig. 3A, western blot analysis revealed that treatment with 5 or $10 \mu \mathrm{g} / \mathrm{ml}$ cordycepin and $50 \mathrm{ng} / \mathrm{ml}$ TRAIL alone for $24 \mathrm{~h}$ did not significantly decrease proteolytic processing of caspase-3, -8 and -9 ; however, combined treatment with cordycepin and TRAIL significantly decreased their levels. Furthermore, we found that cleavage of key death substrates indicates activation of effector caspases such as PARP and $\beta$-catenin (activated-caspase-3 substrates) $(26,27)$. As a result, combined treatment with cordycepin and TRAIL significantly induced cleavage of PARP and $\beta$-catenin in Hep3B cells, whereas treatment with cordycepin or TRAIL alone did not. Additionally, cell lysates containing equal amounts of total protein from cells were assayed to assess in vitro caspase activity. As shown in Fig. 3B, a combined treatment with 

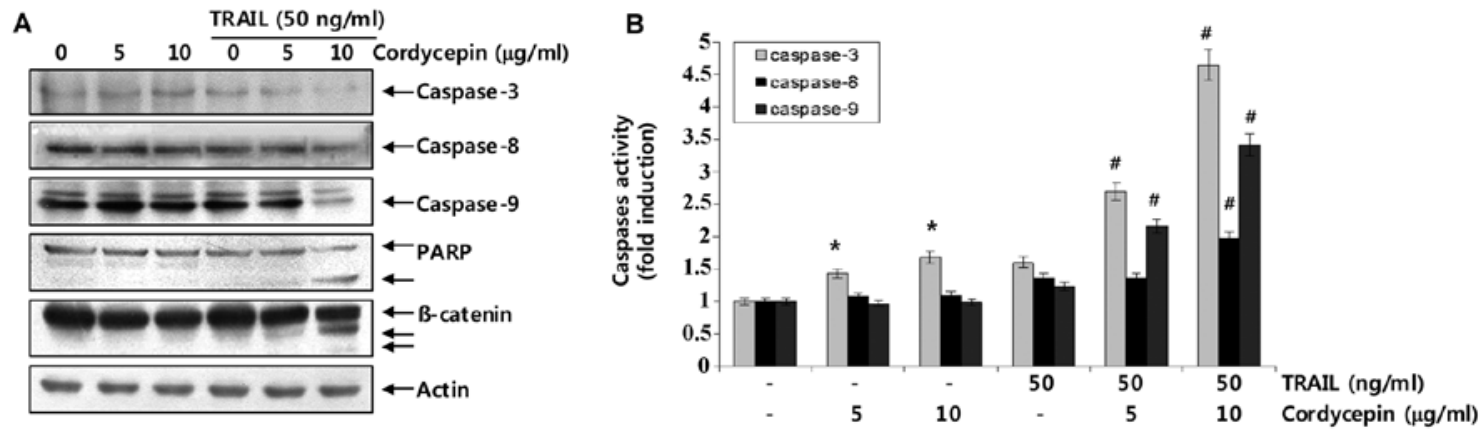

Figure 3. Activation of caspases and degradation of PARP and $\beta$-catenin proteins by combined treatment with cordycepin and TRAIL in Hep3B cells. (A) Cells were pretreated with the indicated concentrations of cordycepin $(50 \mu \mathrm{M})$ for $30 \mathrm{~min}$, and subsequently incubated with TRAIL (50 ng/ml) for $24 \mathrm{~h}$. Cells were lysed and then equal amounts of cell lysates were separated on SDS-polyacrylamide gels and transferred to nitrocellulose membranes. The membranes were probed with the indicated antibodies. An ECL detection system was used to visualize the proteins. Actin was used as the internal control. (B) Cells grown under the same conditions as A were collected and lysed. Aliquots were incubated with DEVD-pNA, IETD-pNA and LEHD-pNA as substrates for caspase-3, -8 and -9 , respectively, at $37^{\circ} \mathrm{C}$ for $1 \mathrm{~h}$, and the released fluorescence products were measured. The statistical significance was obtained from three independent experiments using the Student's t-test ( ${ }^{*} \mathrm{p}<0.05$ vs. untreated control; ${ }^{*} \mathrm{p}<0.05$ vs. TRAIL-treated cells).
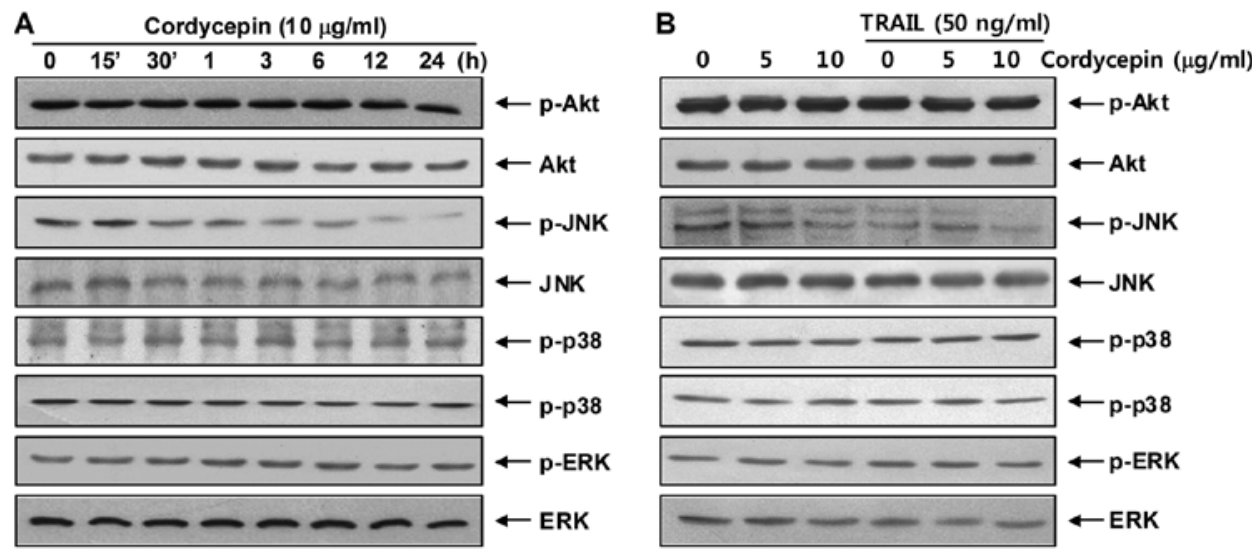

Figure 4. Effects of cordycepin and TRAIL on Akt and MAPK phosphorylation in Hep3B cells. Cells were treated with $10 \mu \mathrm{g} / \mathrm{ml}$ cordycepin for $30 \mathrm{~min}$ and further treated (A) without or (B) with $50 \mathrm{ng} / \mathrm{ml}$ TRAIL (B) for the indicated lengths of time. Equal amounts of cell lysates were resolved on SDS-polyacrylamide gels, transferred to nitrocellulose membranes and probed with the indicated antibodies.

cordycepin and TRAIL significantly increased caspase- $3,-8$, and -9 activities in Hep3B cells. These results indicate that co-treatment induces apoptotic death in Hep3B cells, at least in part, through a caspase-dependent pathway.

Effects of mitogen-activated protein kinases (MAPKs) on cordycepin plus TRAIL-induced apoptosis. Recent studies have revealed that phosphoinositide 3-kinase (PI3K)/Akt and the MAPK signaling pathways are important regulators during apoptotic cell regulation as a TRAIL sensitizing signal pathway $(28,29)$. To investigate the roles of Akt and MAPKs in mediating the observed apoptotic response, western blot analysis was used to assess the change in Akt, JNK, ERK, and p38 MAPK phosphorylation. As shown in Fig. 4, treatment with cordycepin decreased only JNK phosphorylation, whereas phosphorylation levels of other kinases, such as Akt, p38 and ERK, did not change. The results also indicate that cordycepin exerted a concentration-dependent effect on JNK dephosphorylation with a fixed concentration of TRAIL. Thus, Hep3B cells were incubated with cordycepin and TRAIL in the presence of SP600125, a well-known JNK inhibitor, to inves- tigate the functional roles of these dephosphorylation events. As shown in Fig. 5A-C, pretreatment with SP600125 markedly increased the morphological changes and condensed chromatin in the nuclei, and the number of cells with sub-G1 DNA content. Consistent with the increase in sub-G1 DNA content, pretreatment with SP600125 significantly increased the growth inhibition induced by the combined treatment (Fig. 5D). These results indicate that the combined treatment with cordycepin and TRAIL triggered the inhibition of JNK activation; therefore, we verified the inhibition of JNK signaling responsible for the TRAIL-sensitizing effect of cordycepin on apoptosis in Hep3B cells. As a result, SP600125 enhanced upregulation of pro-apoptotic protein Bax levels and downregulation of anti-apoptotic Bcl-2, Bcl-xL and IAP family protein levels in TRAIL and cordycepin-treated Hep3B cells (Fig. 6A). Moreover, SP600125 enhanced caspase activities, as well as PARP and $\beta$-catenin cleavage under the same experimental conditions. Taken together, these findings suggest that the JNK signaling pathway acts as a key regulator of apoptosis in response to the combined cordycepin and TRAIL treatment in Hep3B cells. 


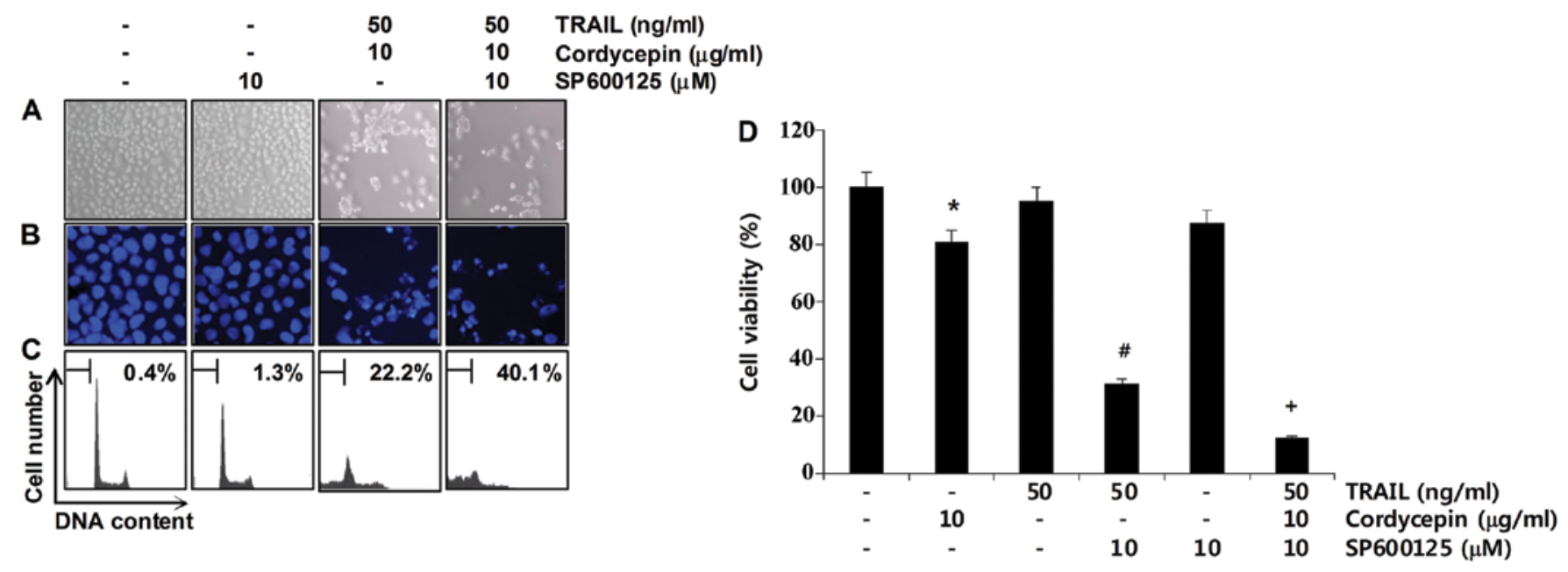

Figure 5. Effects of a JNK inhibitor on apoptosis induced by co-treatment with cordycepin and TRAIL in Hep3B cells. Cells were pretreated with $10 \mu \mathrm{M}$ SP600125 for $1 \mathrm{~h}$ before combined treatment with cordycepin and TRAIL for $24 \mathrm{~h}$. (A) Cell morphology was visualized using an inverted microscope. (B) Cells were stained with DAPI solution after fixation. Stained nuclei were then observed under a fluorescence microscope using a blue filter (magnification, x400). (C) To quantify the degree of apoptosis, cells were evaluated for sub-G1 DNA content, which represents fractions undergoing apoptotic DNA degradation, using a flow cytometer. Results are expressed as means \pm standard deviation of 2 separate experiments. (D) Cell viability was assessed by the MTT assay. Statistical significance was obtained from 3 independent experiments using the Student's t-test ( $\mathrm{p}<0.05 \mathrm{vs}$. untreated control; ${ }^{\#} \mathrm{p}<0.05 \mathrm{vs}$. TRAIL-treated cells; ${ }^{+} \mathrm{p}<0.05$ vs. cordycepin plus TRAIL).
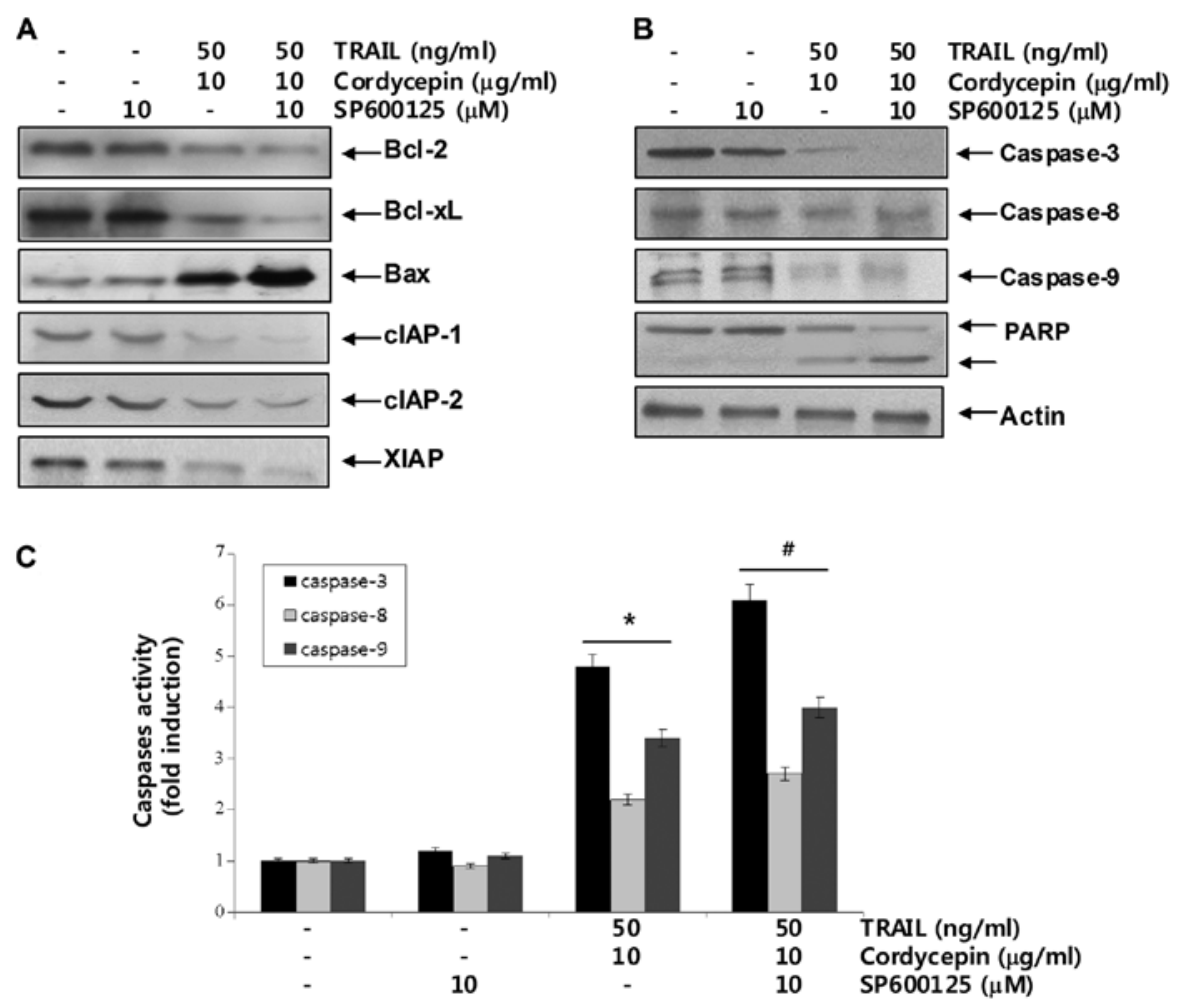

Figure 6. Effects of a JNK inhibitor on modulation of apoptosis-related proteins and caspase activity following co-treatment of Hep3B cells with cordycepin and TRAIL. Cells were pretreated with $10 \mu \mathrm{M}$ SP600125 for $1 \mathrm{~h}$ before combined treatment with cordycepin and TRAIL for $24 \mathrm{~h}$. (A and B) Equal amounts of cell lysates were resolved by SDS-polyacrylamide gel electrophoresis, transferred to nitrocellulose membranes and probed with the indicated antibodies. Actin was used as the internal control. (C) Caspase- $3,-8$ and -9 activity was determined using caspase assay kits according to the manufacturer's protocol. Data are expressed as means \pm standard deviation of 3 independent experiments. Significant differences were determined using the Student's $t$-test $\left({ }^{*} \mathrm{p}<0.05 \mathrm{vs}\right.$. untreated control; $"$ p $<0.05$ vs. cordycepin plus TRAIL).

\section{Discussion}

TRAIL is a member of the TNF superfamily and is able to trigger programmed cell death. When cells receive the cell death signal, TRAIL binds its receptors, such as DR4 and DR5, which are located at the cell surface, and form a deathinducing signaling complex (DISC) that triggers activation of the caspase cascade $(1,2)$. As results, TRAIL initiates 
the extrinsic cell death pathway through formation of DISC and activation of caspases $(2,30,31)$. In addition, TRAIL is relatively non-toxic to normal cells, but it can selectively induce apoptotic cell death in many types of transformed or malignant cells. Thus, TRAIL is a major mediator of acquired immune tumor surveillance and is currently being tested in clinical trials as a novel cancer therapy. However, recent reports have demonstrated that many cancer cells, including the hepatocellular carcinoma Hep3B cell line $(3,11)$, develops resistance to the apoptotic effects of TRAIL. In this study, we assessed the sensitizing effects of cordycepin on TRAIL-induced apoptosis in TRAIL-resistant hepatocellular carcinoma Hep3B cells.

The process of apoptosis is controlled by a wide range of cellular signals, which can be divided into extrinsic and intrinsic pathways. Apoptosis requires caspase activity, and caspases become active when cleaved. Adaptor proteins facilitate the auto-cleavage of initiator caspases (e.g., caspase- 8 and -9), initiator caspases cleave effector caspases (e.g., caspase-3 and -7), and effector caspases disrupt the cell function to elicit cell death $(21,22)$. Two events signal adaptor-mediated caspase cleavage: the binding of ligands to death receptors (the death receptor pathway), and the release of apoptotic factors such as cytochrome $c$ from mitochondria (the mitochondrial pathway). Death receptors activate caspase-8, whereas cytochrome $c$ activates caspase-9. Caspase-3 is common to both pathways. Many proteins modulate apoptotic signaling when apoptosis occurs, including the Bcl-2 and IAP family proteins (22-24). The Bcl-2 proteins such as multidomain apoptotic (Bax and Bak), single domain apoptotic (termed BH3-only), and anti-apoptotic (Bcl-2 and $\mathrm{Bcl}-\mathrm{xL}$ ) proteins damage or protect mitochondria $(32,33)$. In contrast, IAPs inactivate cleaved caspases; thus, they impede the apoptotic process once it has begun. Caspases targeted by IAPs include caspase- 9 and -3 but not caspase- 8 (24,25). Our results showed that treatment with TRAIL in combination with nontoxic concentrations of cordycepin sensitized TRAIL-resistant Hep3B cells to TRAIL-mediated apoptosis. Stimulation by cordycepin and TRAIL increased chromatin condensation and the sub-G1 phase DNA content (Fig. 1). This apoptosis was associated with downregulation of the IAP family members, such as cIAP-1, -2 and XIAP, and antiapoptotic Bcl-2 and Bcl-xL, and upregulation of pro-apoptotic Bax (Fig. 2). We also demonstrated that treatment with TRAIL and cordycepin facilitated activation of caspase-3, -8 and -9, and concomitant degradation of PARP and $\beta$-catenin (Fig. 3). These data suggest that apoptosis induced by co-treatment with cordycepin and TRAIL was caspase-dependent.

The PI3K/Akt and MAPK signaling pathways have been associated with cellular functions as well as TRIAL-mediatedapoptosis $(28,34)$. In general, many reports have described the crucial function of the PI3K/Akt signaling pathway in survival of cancer cells, and inhibition of the PI3K/Akt pathway sensitizes cancer cells to TRAIL-mediated caspase-dependent apoptosis $(29,30)$. Among MAPKs, the JNK and p38 MAPK pathways are frequently associated with induction of apoptosis through caspase activation, whereas the ERK pathway is thought to deliver survival signals that protect cells from TRAIL-mediated apoptosis (35-37). However, increasing evidence indicates that under certain conditions, JNK and p38 MAPK may induce anti-apoptotic, proliferative and cell survival signals in response to a specific stimulus, and ERK activation also results in TRAIL-mediated apoptosis in certain cell types (38-41). However the molecular mechanisms that link TRAIL-mediated apoptosis to kinase activation are still not completely understood. Our results showed that treatment with TRAIL and cordycepin selectively inhibited phosphorylation of JNK (Fig. 4) and the JNK inhibitor SP600125 inhibited cell viability more than co-treatment with cordycepin and TRAIL and increased the sub-G1 population (Fig. 5). Additionally, SP600125 enhanced modulation of the Bcl-2 family, inhibition of the IAP family, and activation of caspases in Hep3B cells treated with cordycepin and TRAIL (Fig. 6). These results strongly suggest that $\mathrm{JNK}$ is a key regulator of apoptosis induction by cordycepin and TRAIL in TRAIL-resistant Hep3B cells.

In summary, our results demonstrate that cordycepin significantly enhanced apoptosis in TRAIL-resistance Hep3B cells by inhibiting JNK signaling. Taken together, our results suggest that $\mathrm{JNK}$ acts as a key regulator of apoptosis in response to combined cordycepin and TRAIL in human hepatocellular carcinoma Hep3B cells. These findings provide novel insight into the clinical application of TRAIL-induced apoptosis in Hep3B cells.

\section{Acknowledgements}

This study was supported by a National Research Foundation of Korea grant funded by the Korean government (20120000897, 2008-0062611) and the Technology Development Program for Agriculture and Forestry (610003-03-1-SU000), Ministry for Food, Agriculture, Forestry and Fisheries, Republic of Korea.

\section{References}

1. Gruss HJ: Molecular, structural, and biological characteristics of the tumor necrosis factor ligand superfamily. Int J Clin Lab Res 26: 143-159, 1996.

2. Bonavida B, Ng CP, Jazirehi A, Schiller G and Mizutani Y: Selectivity of TRAIL-mediated apoptosis of cancer cells and synergy with drugs: The trail to non-toxic cancer therapeutics (Review). Int J Oncol 15: 793-802, 1999.

3. Koschny R, Ganten TM, Sykora J, Haas TL, Sprick MR, Kolb A Stremmel W and Walczak H: TRAIL/bortezomib cotreatment is potentially hepatotoxic but induces cancer-specific apoptosis within a therapeutic window. Hepatology 45: 649-658, 2007.

4. Secchiero P, Vaccarezza M, Gonelli A and Zauli G: TNF-related apoptosis-inducing ligand (TRAIL): a potential candidate for combined treatment of hematological malignancies. Curr Pharm Des 10: 3673-3681, 2004.

5. Bin L, Thorburn J, Thomas LR, Clark PE, Humphreys R and Thorburn A: Tumor-derived mutations in the TRAIL receptor DR5 inhibit TRAIL signaling through the DR4 receptor by competing for ligand binding. J Biol Chem 282: 28189-28194, 2007.

6. Lee SH, Shin MS, Kim HS, Lee HK, Park WS, Kim SY, Lee JH, Han SY, Park JY, Oh RR, Kang CS, Kim KM, Jang JJ, Nam SW, Lee JY and Yoo NJ: Somatic mutations of TRAIL-receptor 1 and TRAIL-receptor 2 genes in non-Hodgkin's lymphoma. Oncogene 20: 399-403, 2001

7. Ito Y, Arita M, Adachi K, Shibata T, Sawai H and Ohno M: Chirally selective synthesis of sugar moiety of nucleosides by chemicoenzymatic approach: L- and D-riboses, showdomycin, and cordycepin. Nucleic Acids Symp Ser 10: 45-48, 1981.

8. Westhof E, Plach H, Cuno I and Lüdemann HD: Proton magnetic resonance studies of 2'-,3'-, and 5'-deoxyadenosine conformations in solution. Nucleic Acids Res 4: 939-953, 1977. 
9. Horowitz B, Goldfinger BA and Marmur J: Effect of cordycepin triphosphate on the nuclear DNA-dependent RNA polymerases and poly(A) polymerase from the yeast, Saccharomyces cerevisiae. Arch Biochem Biophys 172: 143-148, 1976.

10. Müller WE, Weiler BE, Charubala R, Pfleiderer W, Leserman L, Sobol RW, Suhadolnik RJ and Schröder HC: Cordycepin analogues of 2',5'-oligoadenylate inhibit human immunodeficiency virus infection via inhibition of reverse transcriptase. Biochemistry 30: 2027-2033, 1991.

11. Chen Y, Chen YC, Lin YT, Huang SH and Wang SM: Cordycepin induces apoptosis of CGTH W-2 thyroid carcinoma cells through the calcium-calpain-caspase 7-PARP pathway. J Agric Food Chem 58: 11645-11652, 2010.

12. Lee HH, Park C, Jeong JW, Kim MJ, Seo MJ, Kang BW, Park JU, Kim GY, Choi BT, Choi YH and Jeong YK: Apoptosis induction of human prostate carcinoma cells by cordycepin through reactive oxygen species-mediated mitochondrial death pathway. Int J Oncol 42: 1036-1044, 2013.

13. Lee SJ, Moon GS, Jung KH, Kim WJ and Moon SK: c-Jun $\mathrm{N}$-terminal kinase 1 is required for cordycepin-mediated induction of $\mathrm{G} 2 / \mathrm{M}$ cell-cycle arrest via p21WAF1 expression in human colon cancer cells. Food Chem Toxicol 48: 277-283, 2010.

14. Lee HJ, Burger P, Vogel M, Friese K and Brüning A: The nucleoside antagonist cordycepin causes DNA double strand breaks in breast cancer cells. Invest New Drugs 30: 1917-1925, 2012.

15. Jeong JW, Jin CY, Park C, Hong SH, Kim GY, Jeong YK, Lee JD, Yoo YH and Choi YH: Induction of apoptosis by cordycepin via reactive oxygen species generation in human leukemia cells. Toxicol In Vitro 25: 817-824, 2011.

16. Won SY and Park EH: Anti-inflammatory and related pharmacological activities of cultured mycelia and fruiting bodies of Cordyceps militaris. J Ethnopharmacol 96: 555-561, 2005.

17. Nakamura K, Konoha K, Yoshikawa N, Yamaguchi Y, Kagota S, Shinozuka K and Kunitomo M: Effect of cordycepin (3'-deoxyadenosine) on hematogenic lung metastatic model mice. In Vivo 19: 137-141, 2005.

18. Yoshikawa N, Kunitomo M, Kagota S, Shinozuka K and Nakamura K: Inhibitory effect of cordycepin on hematogenic metastasis of B16-F1 mouse melanoma cells accelerated by adenosine-5'-diphosphate. Anticancer Res 29: 3857-3860, 2009.

19. Lee EJ, Kim WJ and Moon SK: Cordycepin suppresses TNF-alpha-induced invasion, migration and matrix metalloproteinase- 9 expression in human bladder cancer cells. Phytother Res 24: 1755-1761, 2010.

20. Tak JK, Lee JH and Park JW: Resveratrol and piperine enhance radiosensitivity of tumor cells. BMB Rep 45: 242-246, 2012.

21. Lemasters JJ, Nieminen AL, Qian T, Trost LC, Elmore SP, Nishimura Y, Crowe RA, Cascio WE, Bradham CA, Brenner DA and Herman B: The mitochondrial permeability transition in cell death: a common mechanism in necrosis, apoptosis and autophagy. Biochim Biophys Acta 1366: 177-196, 1998.

22. Fernández-Luna JL: Apoptosis regulators as targets for cancer therapy. Clin Transl Oncol 9: 555-562, 2007.

23. Aggarwal BB, Bhardwaj U and Takada Y: Regulation of TRAILinduced apoptosis by ectopic expression of antiapoptotic factors. Vitam Horm 67: 453-483, 2004.

24. Wen X, Lin ZQ, Liu B and Wei YQ: Caspase-mediated programmed cell death pathways as potential therapeutic targets in cancer. Cell Prolif 45: 217-224, 2012.

25. Patwardhan GA and Liu YY: Sphingolipids and expression regulation of genes in cancer. Prog Lipid Res 50: 104-114, 2011.
26. Lazebnik YA, Kaufmann SH, Desnoyers S, Poirier GG and Earnshaw WC: Cleavage of poly(ADP-ribose) polymerase by a proteinase with properties like ICE. Nature 371: 346-347, 1994.

27. Fukuda K: Apoptosis-associated cleavage of $\beta$-catenin in human colon cancer and rat hepatoma cells. Int J Biochem Cell Biol 31: 519-529, 1999.

28. Frese S, Pirnia F, Miescher D, Krajewski S, Borner MM, Reed JC and Schmid RA: PG490-mediated sensitization of lung cancer cells to Apo2L/TRAIL-induced apoptosis requires activation of ERK2. Oncogene 22: 5427-5435, 2003.

29. Falschlehner C, Emmerich $\mathrm{CH}$, Gerlach B and Walczak H: TRAIL signalling: decisions between life and death. Int $\mathrm{J}$ Biochem Cell Biol 39: 1462-1475, 2007.

30. Secchiero P, Gonelli A, Carnevale E, Milani D, Pandolfi A, Zella D and Zauli G: TRAIL promotes the survival and proliferation of primary human vascular endothelial cells by activating the Akt and ERK pathways. Circulation 107: 2250-2256, 2003.

31. Seo OW, Kim JH, Lee KS, Lee KS, Kim JH, Won MH, Ha KS, Kwon YG and Kim YM: Kurarinone promotes TRAIL-induced apoptosis by inhibiting NF- $\kappa \mathrm{B}$-dependent cFLIP expression in HeLa cells. Exp Mol Med 44: 653-664, 2012.

32. Ola MS, Nawaz M and Ahsan H: Role of Bcl-2 family proteins and caspases in the regulation of apoptosis. Mol Cell Biochem 351: 41-58, 2011.

33. Brenner D and Mak TW: Mitochondrial cell death effectors. Curr Opin Cell Biol 21: 871-877, 2009.

34. Thakkar H, Chen X, Tyan F, Gim S, Robinson H, Lee C, Pandey SK, Nwokorie C, Onwudiwe N and Srivastava RK: Pro-survival function of Akt/protein kinase B in prostate cancer cells. Relationship with TRAIL resistance. J Biol Chem 276: 38361-38369, 2001.

35. Tran SE, Holmstrom TH, Ahonen M, Kahari VM and Eriksson JE: MAPK/ERK overrides the apoptotic signaling from Fas, TNF, and TRAIL receptors. J Biol Chem 276: 16484-16490, 2001.

36. Söderström TS, Poukkula M, Holmström TH, Heiskanen KM and Eriksson JE: Mitogen-activated protein kinase/extracellular signal-regulated kinase signaling in activated $\mathrm{T}$ cells abrogates TRAIL-induced apoptosis upstream of the mitochondrial amplification loop and caspase-8. J Immunol 169: 2851-2860, 2002.

37. Jurewicz A, Matysiak M, Andrzejak S and Selmaj K: TRAIL-induced death of human adult oligodendrocytes is mediated by JNK pathway. Glia 53: 158-166, 2006.

38. Mühlenbeck F, Haas E, Schwenzer R, Schubert G, Grell M, Smith C, Scheurich P and Wajant H: TRAIL/Apo2L activates c-Jun $\mathrm{NH}_{2}$-terminal kinase (JNK) via caspase-dependent and caspase-independent pathways. J Biol Chem 273: 33091-33098, 1998.

39. Qu J, Zhao M, Teng Y, Zhang Y, Hou K, Jiang Y, Yang X, Shang $\mathrm{H}, \mathrm{Qu} \mathrm{X}$ and Liu Y: Interferon- $\alpha$ sensitizes human gastric cancer cells to TRAIL-induced apoptosis via activation of the c-CBL-dependent MAPK/ERK pathway. Cancer Biol Ther 12: 494-502, 2011.

40. Gupta SC, Reuter S, Phromnoi K, Park B, Hema PS, Nair M and Aggarwal BB: Nimbolide sensitizes human colon cancer cells to TRAIL through reactive oxygen species- and ERK-dependent up-regulation of death receptors, p53, and Bax. J Biol Chem 286: 1134-1146, 2011.

41. Phipps LE, Hino S and Muschel RJ: Targeting cell spreading: a method of sensitizing metastatic tumor cells to TRAIL-induced apoptosis. Mol Cancer Res 9: 249-258, 2011. 